\title{
O papel do Enfermeiro Intensivista no processo de morte: uma revisão integrativa da literatura
}

The role of the intensivist nurse in the death process: an integrative literature review

El papel de la enfermera intensivista en el proceso de defunción: una revisión integrativa de la literatura

Ana Gracinda Ignácio da Silva ${ }^{1 *}$, Brenda Regina Farias Carneiro ${ }^{1}$, Carolline de Nazaré Silva da Cruz $^{1}$, Regiane Silveira da Luz ${ }^{1}$, Gabriel Fazzi Costa ${ }^{1}$, Marcelina Ribeiro da Silva ${ }^{1}$, Pedrinha do Socorro Castro dos Prazeres ${ }^{1}$, Juliana Conceição Dias Garcez ${ }^{1}$, Daniele Melo Sardinha ${ }^{2}$.

\section{RESUMO}

Objetivo: Levantar evidências científicas na literatura do período de 2014 a 2018, sobre a vivência dos enfermeiros que trabalham em unidade de terapia intensiva diante do processo de morte. Métodos: Trata-se de uma Revisão Integrativa da Literatura, realizada nas bases de dados LILACS, SCIELO e BDENF, com a utilização dos descritores: Unidade de Terapia Intensiva; Enfermagem; Morte; e Morrer. Resultados: A amostra final constitui-se em 13 artigos. Foram identificadas duas categorias temáticas: 1) A inversão da ordem natural do ciclo de vida: os enfermeiros vivenciam o processo de morte na UTI com tristeza, impotência, angústia e choque, no entanto precisam ser fortes frente a família para poder acolhê-las e confortá-las; 2) Quando a morte vence a tecnologia assistencial: é um evento que abate a enfermagem pois, apesar do uso de todos os recursos que a unidade possui, de nada vale para esses pacientes, restando o cuidado de enfermagem de conforto e alívio. Considerações finais: A vivência dos enfermeiros diante do processo de morte é permeada de sentimentos de angústia, estresse, impotência e cuidados para com o paciente antes, durante e pós morte, assim como, de conforto e apoio aos familiares e sua equipe.

Palavras-chave: Unidade de Terapia Intensiva, Enfermagem, Morte, Morrer.

\begin{abstract}
Objective: To raise scientific evidence in the literature from 2014 to 2018, on the experience of nurses working in intensive care units in the face of the death process. Methods: This is an integrative literature review, carried out in the databases LILACS, SCIELO and BDENF, using the descriptors: Intensive Care Unit; Nursing; Death; and Die. Results: The final sample consisted of 13 articles. Two thematic categories were identified: 1) The inversion of the natural order of the life cycle: the nurses experience the process of death in the ICU with sadness, impotence, anguish and shock, however need to be strong in front of the family in order to accept them and Comfort them; 2) When death wins the assistive technology: It is an event that hurts nursing because, despite the use of all the resources that the unit possesses, nothing is worth to these patients, remaining nursing care of comfort and relief. Final considerations: The experience of nurses in the process
\end{abstract}

\footnotetext{
${ }^{1}$ Centro Universitário Metropolitano da Amazônia (UNIFAMAZ), Belém-Pará. *E-mail: anagracinda08@gmail.com

${ }^{2}$ Instituto Evandro Chagas (IEC), Ananindeua-Pará.
}

SUBMETIDO EM: 9/2019

ACEITO EM: 10/2019

PUBLICADO EM: 11/2019 
of death is permeated with feelings of anguish, stress, impotence and care for the patient before, during and after death, as well as comfort and support for relatives and their team.

Key words: Intensive Care Unit, Nursing, Death, Dying.

\section{RESUMEN}

Objetivo: Elevar la evidencia científica en la literatura de 2014 a 2018, sobre la experiencia de las enfermeras que trabajan en unidades de cuidados intensivos frente al proceso de defunción. Métodos: Se trata de una revisión integrativa de la literatura, realizada en las bases de datos LILACS, SCIELO y BDENF, utilizando los descriptores: Unidad de Cuidados Intensivos; Enfermería; Muerte; y Morir. Resultados: La muestra final consistió en 13 artículos. Se identificaron dos categorías temáticas: 1) La inversión del orden natural del ciclo de vida: las enfermeras experimentan el proceso de muerte en la $\mathrm{UCI}$ con tristeza, impotencia, angustia y shock, sin embargo necesitan ser fuertes frente a la familia para aceptarlos y confortarlos; 2) Cuando la muerte gana la tecnología de asistencia: Es un evento que afecta la enfermería porque, a pesar del uso de todos los recursos que posee la unidad, nada vale la pena para estos pacientes, permaneciendo cuidados de enfermería de comodidad e alivio. Consideraciones finales: La experiencia de las enfermeras en el proceso de la muerte está impregnada de sentimientos de angustia, estrés, impotencia y cuidado del paciente antes, durante y después de la muerte, así como comodidad y apoyo para los familiares y su equipo.

Palabras clave: Unidad de Cuidados Intensivos, Enfermería, Muerte, Muerte.

\section{INTRODUÇÃO}

Nos últimos anos houve um crescente interesse por parte de pesquisadores e estudantes sobre o estudo da Tanatologia - ciência que estuda as causas e os fenômenos relacionados à morte. Tal fato tem contribuído para o desenvolvimento dessa área, entretanto, devido a questões culturais, ainda existem estigmas ao tratar sobre a temática da morte e isto acaba gerando certa estranheza àqueles que resolvem torná-la objeto de estudo (SILVA RS, et al., 2015).

A experiência da morte é um processo singular e individual, e a forma como as pessoas envolvidas familiares e profissionais de saúde - lidam com este acontecimento depende de fatores culturais como valores e crenças que possuem (VENTURA G, et al. 2019). Disto isto, não é possível prever como o indivíduo irá vivenciar o luto, não existe um padrão ou fórmula para mitigar a dor da perda de um ente querido, por isso este momento deve ser respeitado dentro das particularidades de cada pessoa. É necessário vivenciar o luto e expressar a dor, demonstrar apoio e solidariedade pode ajudar neste processo (SILVA VA, et al., 2019).

Os significados associados às perdas inerentes à vida humana decorrem das experiências vividas e são fundamentais para o ajustamento do indivíduo ao luto, podem mudar à medida que novas experiências são vivenciadas. Sabendo que os significados são mutáveis, analisar e entender como se dá esse processo passa pelo estudo dos relacionamentos, da linguagem e da interação humana com o meio que o cerca (SANTOS MR, et al., 2019). A morte possui impacto perturbador sobre o equilíbrio funcional, as reações emocionais dependem do nível de integração entre os sujeitos e a importância funcional que o membro perdido desempenhava. Esses fatores influenciam na adaptação dos familiares diante da perda e até mesmo podem contribuir para o desencadeamento de problemas emocionais a longo prazo (MONTEIRO MC, et al., 2017).

Deve-se considerar que no caso dos profissionais da saúde, essa vivência poderá afetar não só sua relação com a morte na condição de ser humano, mas também na sua atuação profissional frente ao paciente. Esse problema é corroborado pela literatura quando refere que talvez, a dificuldade de lidar com a morte inicia na formação acadêmica dos profissionais de saúde, visto que a temática morte é negligenciada ou até inexistente, pois a grade curricular privilegia a técnica (BARBOSA AMGC e MASSARONI L, 2016). 
No entanto, existem várias unidades hospitalares onde lidar com processo de morte é iminente, uma dessas unidades em que diariamente, a equipe de enfermagem pode lidar com o processo de morte a qualquer momento, são as Unidades de Terapia Intensiva (UTIs). Sendo assim, o enfermeiro lida com o morrer e a morte e, consequentemente, está mais suscetível a níveis elevados de estresse (BARRETO VPDC, et al., 2017). Toda essa problemática nos inquietou e motivou a curiosidade em buscar na literatura científica do período de 2014 a 2018 evidências científicas sobre: Como os enfermeiros que atuam em uma unidade de terapia intensiva vivenciam o processo de morte dos pacientes?

O estudo é relevante pois, possibilitou sistematizar conhecimento sobre o tema em questão o que certamente, ajudará profissionais e acadêmicos da área a conhecer como esse processo vem acontecendo e refletir, sobre a necessidade de apoio profissional, assim como, da necessidade de melhor preparo dos profissionais para lidar com tal processo. Objetivou-se com a pesquisa, levantar evidências científicas na literatura sobre a vivência dos enfermeiros que trabalham em unidade de terapia intensiva, diante do processo de morte.

\section{MÉTODOS}

Trata-se de uma pesquisa exploratória, com abordagem qualitativa do tipo Revisão Integrativa da Literatura (RIL). Para a realização deste estudo foram utilizadas as seguintes etapas conforme indicadas na Figura 1. Para atender a primeira etapa do método, partiu-se da questão norteadora: Como os enfermeiros que atuam em unidade de terapia intensiva vivenciam o processo de morte dos pacientes?

Figura 1 - Fluxograma das etapas da revisão integrativa.

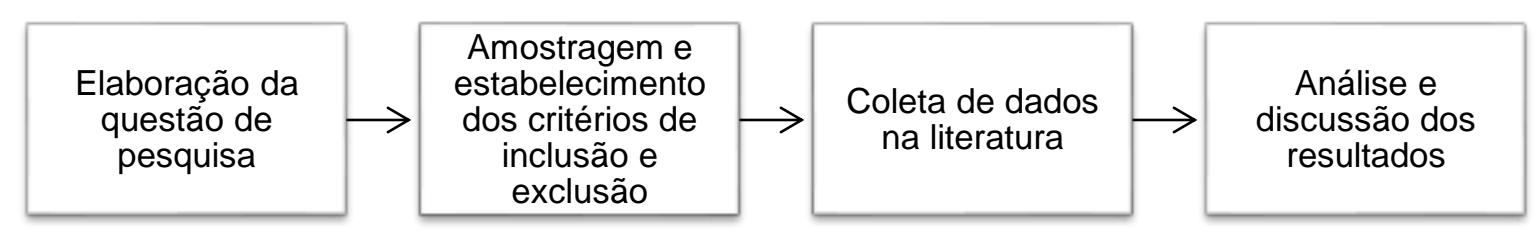

Fonte: adaptado de Mendes KDS, et al., 2008.

Em seguida estabelece-se como critérios de inclusão: artigos na íntegra, em língua portuguesa do Brasil disponíveis em base de dados online no período de 2014 a 2018 e que retratem a temática. Como critérios de exclusão: artigos repetidos em bases de dados online. Para busca de artigos foram utilizados os seguintes descritores controlados: Unidade de Terapia Intensiva; Enfermagem; Morte; e Morrer. Os descritores foram combinados utilizando-se os termos booleanos "and" e "or". Foram utilizadas as seguintes bases de dados: Literatura Latino-Americana e do Caribe (LILACS). A Scientific Electronic Library Online (SCIELO) e a Base de Dados Bibliográfica Especializada na área de Enfermagem (BDENF). A partir da leitura dos resumos, foram identificados os artigos que atendiam ao propósito do estudo e respondiam à questão norteadora.

Para coleta de dados, utilizou-se o instrumento de Ursi (URSI ES e GAVÃO CM, 2006) e a partir do mesmo foram registrados todos os dados de cada artigo de interesse para o estudo, assim como verificadas suas classificações de acordo com as evidências e classificados de forma hierárquica. A discussão foi realizada com base em autores que fundamentaram o estudo.

Portanto, para sistematização dos dados produzidos com a revisão, foi elaborado um quadro de evidências, e a partir dele visualizado as convergências e divergências, sendo o ponto de partida para identificação das categorias temáticas.

\section{RESULTADOS}

Utilizando os descritores combinados: Morte e morrer e enfermagem e UTI, foram encontrados na base de dados LILACS 335 artigos, após leitura dos resumos 9 estavam dentro do proposto. Na base de dados 
SCIELO, foram encontrados 70 artigos, 2 estavam dentro do proposto. E na base de dados BDENF, 70 artigos dos quais apenas 2 atendem aos objetivos do estudo. Portanto, do universo de 475 artigos de trabalhos científicos relacionados ao tema, somente 13 estavam dentro da temática. A seguir descreve-se os resultados da estratégia de busca adotada.

Figura 2 - Fluxograma da seleção dos estudos segundo o Preferred Reporting Items for Systematic Reviews and Meta-Analyses (PRISMA 2009). Belém (PA), Brasil, 2019.

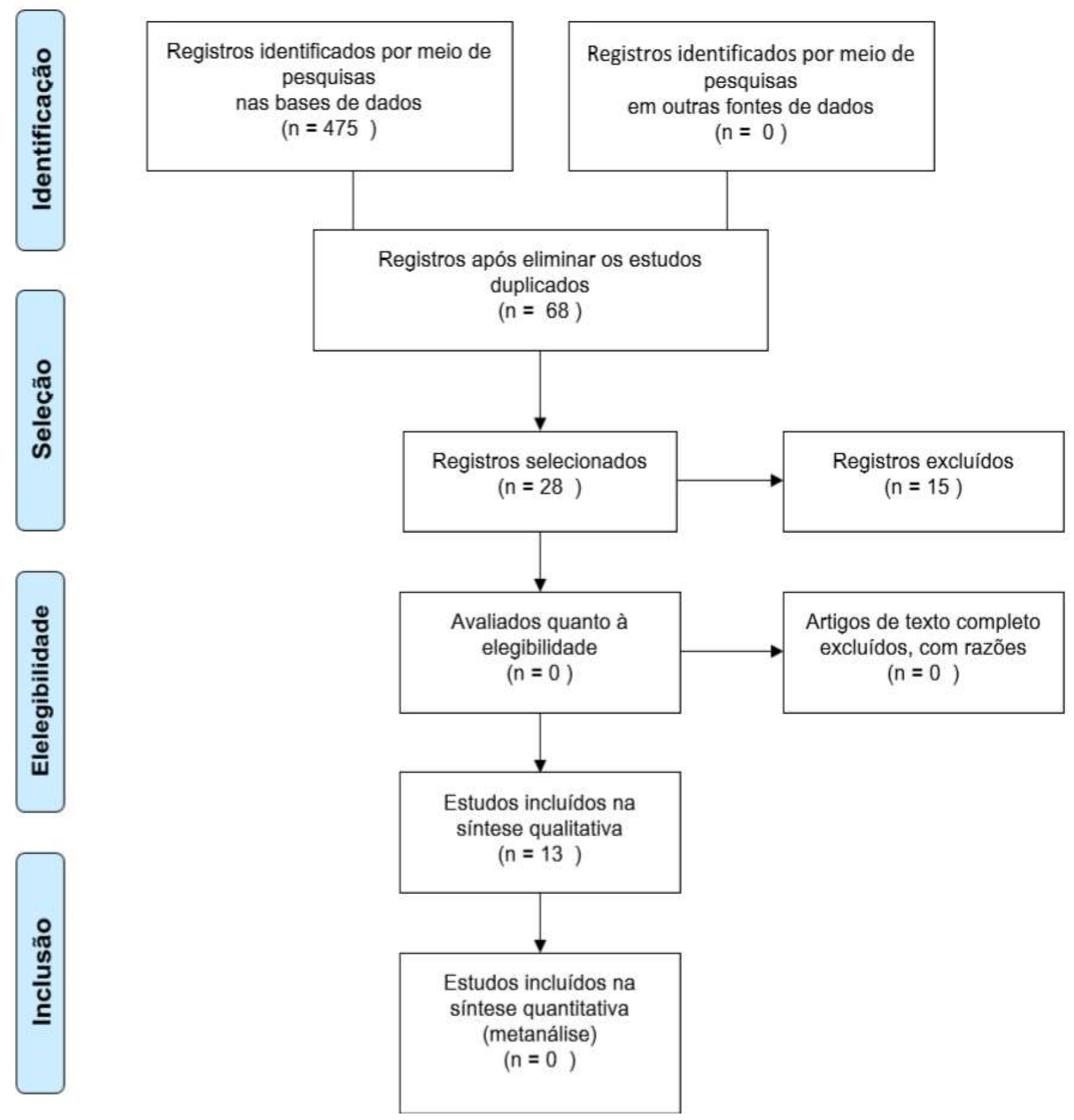

Fonte: Silva AGI, et al., 2019.

Evidenciou-se na leitura dos artigos, que a maioria dos enfermeiros que trabalham em UTls são constituídos de mulheres e a maioria dos artigos incluídos na revisão foram de cunho estudo de campo, descritivo e exploratório, portanto, com nível de evidência 4, conforme apresentado no quadro a seguir. 
Quadro 1 - Artigos Selecionado e nível de evidências. Belém-PA, Brasil 2019.

\begin{tabular}{|c|c|c|c|c|}
\hline ARTIGO/BASE DE DADOS & AUTORES & TIPO DE ESTUDO & NE & RESULTADOS \\
\hline $\begin{array}{l}\text { LILACS } \\
\text { 1. Processo de morrer em unidade de } \\
\text { terapia intensiva pediátrica. }\end{array}$ & $\begin{array}{l}\text { Souza PSN, } \\
\text { Conceição AOF, } \\
2018 .\end{array}$ & Original Qualitativo & NÍVEL-4 & $\begin{array}{l}\text { Tristeza, por apego a criança, principalmente de longo tempo. } \\
\text { Preocupação com a família. } \\
\text { Impotência pôr a doença ter vencido. } \\
\text { Precisa ser forte pela família do paciente. } \\
\text { Fazer com que a morte seja suave para o paciente. } \\
\text { Confortar e acolher familiares. } \\
\text { Angústia- tentam não chorar, mas choram no banheiro. } \\
\text { Choque: Processo de trabalho, clima na unidade são afetados. } \\
\text { Recuperação para ajudar as outras crianças. }\end{array}$ \\
\hline $\begin{array}{l}\text { LILACS } \\
\text { 2. Entre o nascer e o morrer: cuidados } \\
\text { paliativos na experiência dos } \\
\text { profissionais de saúde. }\end{array}$ & $\begin{array}{l}\text { Alves AMF, et } \\
\text { al., 2018. }\end{array}$ & Original Qualitativo & NÍVEL-4 & $\begin{array}{l}\text { Em cuidados paliativos, mesmo na UTIN- Bem difícil. } \\
\text { Conforto para não sentir dor. } \\
\text { Resistência por ser um bebê. } \\
\text { Discussão sobre o assunto, necessidade de uma abordagem, apoio tanto para } \\
\text { profissionais como para família. } \\
\text { Esconder a dor- ver que muitas vezes esses bebês são os últimos a serem } \\
\text { vistos e prescritos, os que sobram, os escondidos. } \\
\text { Sentimento de pena- da mãe, família do bebê. } \\
\text { Procuram criar vínculo entre mãe e bebê, tocam, pois, acreditam que ele } \\
\text { sente. }\end{array}$ \\
\hline
\end{tabular}




\section{Revista Eletrônica Acervo Saúde / Electronic Journal Collection Health ｜ ISSN 2178-2091}

\begin{tabular}{|c|c|c|c|c|}
\hline $\begin{array}{l}\text { LILACS } \\
\text { 3. Processo de morte e morrer em } \\
\text { unidade de terapia intensiva neonatal à } \\
\text { luz da complexidade. }\end{array}$ & $\begin{array}{l}\text { Subutzki LS, et } \\
\text { al., } 2018 \text {. }\end{array}$ & Original Qualitativo & NÍVEL-4 & $\begin{array}{l}\text { A morte de um neonato, à interrupção da ordem natural do ciclo vital, foge do } \\
\text { normal. } \\
\text { Reconhecem que se encontram diante de um evento para o qual não } \\
\text { encontram respostas prontas. } \\
\text { Impotência, de intenso desgaste físico e emocional diante do processo de } \\
\text { morte de uma criança, sobretudo no contato com a família. } \\
\text { Paralisação, não encontraram palavras para confortar os pais nem mesmo } \\
\text { explicações. } \\
\text { Tristeza e a sensação de que pouco ou nada fizeram para salvar a criança } \\
\text { Desperta uma autorreflexão e autoanálise relacionadas às relações de } \\
\text { trabalho, às relações familiares. Repensar em atitudes pessoais e } \\
\text { profissionais. }\end{array}$ \\
\hline $\begin{array}{l}\text { LILACS } \\
\text { 4. Conhecendo as práticas de cuidado } \\
\text { da equipe de enfermagem em relação } \\
\text { ao cuidado na situação de final de vida } \\
\text { de recém-nascidos. }\end{array}$ & $\begin{array}{l}\text { Silva IN, et al., } \\
2017 .\end{array}$ & Original Qualitativo & NÍVEL-4 & $\begin{array}{l}\text { Momento obscuro, confuso e incompreensível, uma vez que relacionam a } \\
\text { morte precoce com a modificação do curso natural da vida, em que os filhos } \\
\text { morrem depois dos pais. } \\
\text { Frustração se mostram diretamente atrelados à experiência de ser enfermeira } \\
\text { de uma UTI Neonatal. } \\
\text { A implantação dos cuidados paliativos no contexto da UTI Neonatal mostra ser } \\
\text { pouco discutida e delineada. } \\
\text { Falta de comunicação. }\end{array}$ \\
\hline
\end{tabular}




\section{Revista Eletrônica Acervo Saúde / Electronic Journal Collection Health ｜ ISSN 2178-2091}

\begin{tabular}{|c|c|c|c|c|}
\hline $\begin{array}{l}\text { LILACS } \\
\text { 5. Terminalidade da vida infantil: } \\
\text { percepções e sentimentos de } \\
\text { enfermeiros. }\end{array}$ & $\begin{array}{l}\text { Menin } \quad \text { GE, } \\
\text { Pettenon } \quad M K, \\
2015 .\end{array}$ & Original Qualitativo & NÍVEL-4 & $\begin{array}{l}\text { Força enorme, adotar um sentimento } \\
\text { de frieza que muitas vezes não lhe pertence. } \\
\text { Segurar o choro, engolir uma lágrima. } \\
\text { Controlar seu emocional, a fim de não se prejudicar nem diminuir seu } \\
\text { desempenho, sentimento de frustração, inutilidade e impotência, estar } \\
\text { preparados para conduzir a equipe, para que o trabalho continue, } \\
\text { proporcionar motivação a sua equipe, } \\
\text { A família necessita de auxílio. } \\
\text { Deixar que eles passem por este momento reagindo do jeito deles, } \\
\text { propicia a flexibilização das normas rígidas de segregação de uma UTI e } \\
\text { valorizar a presença dos pais e familiares em todo o processo. }\end{array}$ \\
\hline $\begin{array}{l}\text { LILACS } \\
\text { 6. Representações sociais de } \\
\text { enfermeiros sobre o processo de morte } \\
\text { e morrer em UTI. }\end{array}$ & $\begin{array}{l}\text { Silva CRL, et al., } \\
2016 .\end{array}$ & Original Qualitativo & NÍVEL-4 & $\begin{array}{l}\text { "A morte como possibilidade concreta na UTI gerando alívio e impotência”. } \\
\text { Significados principais evidenciados são os sentimentos de alívio do } \\
\text { sofrimento e de sensação de impotência, uma forma de alívio, solução da dor, } \\
\text { da angústia envolvida neste processo, é um modus operandi que esses } \\
\text { profissionais encontraram para se protegerem do sofrimento psíquico que } \\
\text { pode decorrer da perda do paciente, mesmo diante de todo aparato } \\
\text { tecnológico disponível nessas unidades. }\end{array}$ \\
\hline $\begin{array}{l}\text { SCIELO } \\
\text { 7. Conforto para uma boa morte: } \\
\text { perspectiva de uma equipe de } \\
\text { enfermagem intensivista. }\end{array}$ & $\begin{array}{l}\text { Silva RS, et al., } \\
2015 .\end{array}$ & Original Qualitativo & NÍVEL-4 & $\begin{array}{l}\text { Conforto: os cuidados de Enfermagem a pacientes em Cuidados Paliativos, o } \\
\text { mesmo cuidado como se fosse ao paciente que não está em cuidado paliativo. } \\
\text { Sinto-me bem e confortável porque entendo que estou oferecendo qualidade e } \\
\text { diminuindo o sofrimento do paciente e da família. } \\
\text { Evitar complicações é frustrante porque vejo o sofrimento da família, é } \\
\text { frustrante porque sei que não tem mais nada para investir naquele paciente, é } \\
\text { frustrante porque eu o vejo sofrendo, e por vezes, sofro junto. }\end{array}$ \\
\hline
\end{tabular}

\footnotetext{
REAS/EJCH | Vol.Sup.37 | e1764 | DOI: https://doi.org/10.25248/reas.e1764.2019 Página 7 de 14
} 


\section{Revista Eletrônica Acervo Saúde / Electronic Journal Collection Health ｜ ISSN 2178-2091}

\begin{tabular}{|c|c|c|c|c|}
\hline $\begin{array}{l}\text { LILACS } \\
\text { 8. Dialética de sentimentos do } \\
\text { enfermeiro intensivista sobre o trabalho } \\
\text { na terapia intensiva. }\end{array}$ & $\begin{array}{l}\text { Cruz EJER, et } \\
\text { al., } 2014 .\end{array}$ & Original Qualitativo & NÍVEL-4 & $\begin{array}{l}\text { As pessoas estão ficando mais velhas, mais doentes, o tratamento se } \\
\text { prolonga. } \\
\text { para no final do dia o paciente morrer e tudo aquilo foi em vão. } \\
\text { Todavia, ainda que na UTI estejam disponíveis recursos tecnológicos } \\
\text { relacionados ao suporte avançado de vida, nem sempre é possível o alcance } \\
\text { desse objetivo maior, salvar. }\end{array}$ \\
\hline $\begin{array}{l}\text { BDENF } \\
\text { 9. Sofrimento moral dos enfermeiros, } \\
\text { em situações de final de vida, em } \\
\text { unidades de terapia intensiva. }\end{array}$ & $\begin{array}{l}\text { Costa MR, et al., } \\
2017 .\end{array}$ & Original Qualitativo & NÍVEL-4 & $\begin{array}{l}\text { Experiências de final de vida } \\
\text { muito difíceis no início da profissão, pois os profissionais ainda não estão } \\
\text { habituados e amadurecidos para lidar com tais circunstâncias. Porém, com o } \\
\text { passar dos anos de profissão, é possível notar que a forma de lidar com essas } \\
\text { experiências torna-se mais tranquila, devido à grande diversidade de } \\
\text { situações vivenciadas relatam que ainda se deparam com situações que os } \\
\text { sensibilizam, comovem, entristecem e frustram, especialmente, em se } \\
\text { tratando de pacientes jovens, dos quais se espera que tenham grande } \\
\text { perspectiva de vida pela frente. } \\
\text { Aceitação da perda do paciente principalmente, com enfermos idosos, } \\
\text { preparar a sua equipe para a morte daquele paciente e, também, dar um } \\
\text { apoio para os familiares. }\end{array}$ \\
\hline $\begin{array}{l}\text { BDENF } \\
\text { 10. Enfrentamento da morte: } \\
\text { enfermagem na unidade de terapia } \\
\text { intensiva. }\end{array}$ & $\begin{array}{l}\text { Dantas MAA, et } \\
\text { al., } 2016 \text {. }\end{array}$ & Revisão Bibliográfica & NÍVEL-4 & $\begin{array}{l}\text { Impotência nos profissionais da saúde. Isso pode ser explicado pelo fato de a } \\
\text { sociedade ter uma expectativa de responsabilização dos profissionais de } \\
\text { manutenção da vida e, quando essa "missão" não pode ser alcançada, surge } \\
\text { ansiedade, angústia e frustração }\end{array}$ \\
\hline
\end{tabular}

\footnotetext{
REAS/EJCH | Vol.Sup.37 | e1764 | DOI: https://doi.org/10.25248/reas.e1764.2019 Página 8 de 14
} 


\section{Revista Eletrônica Acervo Saúde / Electronic Journal Collection Health ｜ ISSN 2178-2091}

\begin{tabular}{|c|c|c|c|c|}
\hline $\begin{array}{l}\text { LILACS } \\
\text { 11. Profissionais de saúde e o processo } \\
\text { de morte e morrer dos pacientes: uma } \\
\text { revisão integrativa. }\end{array}$ & $\begin{array}{l}\text { Perboni JS, et } \\
\text { al., } 2018 \text {. }\end{array}$ & $\begin{array}{l}\text { Artigo de Revisão } \\
\text { bibliográfica-RIL }\end{array}$ & NÍVEL-4 & $\begin{array}{l}\text { Os profissionais da saúde estão despreparados para lidar com o processo de } \\
\text { fim de vida; além disso, sentem a falta de uma melhor atenção para o tema, } \\
\text { principalmente o relacionado a estratégias de enfrentamento. }\end{array}$ \\
\hline $\begin{array}{l}\text { LILACS } \\
\text { 12. Sentimentos vivenciados pelos } \\
\text { profissionais de Enfermagem diante de } \\
\text { morte em unidade de terapia intensiva } \\
\text { neonatal. }\end{array}$ & $\begin{array}{l}\text { Rocha DD, et } \\
\text { al., } 2017 .\end{array}$ & $\begin{array}{l}\text { Revisão Integrativa da } \\
\text { Literatura }\end{array}$ & NÍVEL-4 & $\begin{array}{l}\text { Tristeza, frustração e estresse pela perda que a morte representa. } \\
\text { Evento fragiliza e assusta a morte tem significado "negativo", provocando. } \\
\text { sinônimo de limitação profissional } \\
\text { Os enfermeiros, quando estão diante de situações de morte, desenvolvem } \\
\text { sentimento de impotência, culpa e raiva. }\end{array}$ \\
\hline $\begin{array}{l}\text { SCIELO } \\
\text { 13. Cuidado paliativo e enfermeiros de } \\
\text { terapia intensiva: sentimentos que } \\
\text { ficam. }\end{array}$ & $\begin{array}{l}\text { Silveira NR, et } \\
\text { al., } 2016 \text {. }\end{array}$ & Original Qualitativo & NÍVEL-4 & $\begin{array}{l}\text { Conforto, frustração, insegurança e angústia, além do sentimento de que a } \\
\text { formação e atuação profissional estão voltados para o curativo. } \\
\text { Diminuindo o sofrimento do paciente e da família. } \\
\text { Têm as duas faces da moeda, por um lado é triste de certa forma, saber que } \\
\text { estou cuidando de uma pessoa que está indo, às vezes, é um cuidado } \\
\text { paliativo de frustração. É frustrante porque vejo o sofrimento da família, } \\
\text { porque sei que não tem mais nada para investir naquele paciente, porque eu o } \\
\text { vejo sofrendo. }\end{array}$ \\
\hline
\end{tabular}

Fonte: Silva AGI, et al., 2019. 
A partir da leitura e análise dos resultados encontrados, foram identificadas duas categorias temáticas: A inversão da ordem natural do ciclo de vida e quando a morte vence a tecnologia assistencial.

\section{Tema 1: A inversão da ordem natural do ciclo de vida}

Dos 13 artigos que compõem este estudo 7 são sobre a vivência dos enfermeiros diante da morte em unidade de terapia infantil ou de neonatologia.

Nesses artigos, observou-se que os enfermeiros vivenciam o processo de morte na UTI com tristeza, impotência, angústia e até em choque algumas vezes. Isso ocorre em virtude do apego a criança, da preocupação com a família e por ter como realidade, que a doença venceu. Por outro lado, elas precisam ser fortes frente a família para poder acolhê-las e confortá-las e ainda, tornar esse momento suave para 0 paciente. A angústia, leva muitas vezes a chorar, ao vivenciar esse momento, não na frente da equipe ou da família, choram sozinhas, como por exemplo, no banheiro, depois se utilizam de medidas que acalmem para retomar o trabalho. A morte de uma criança afeta o processo de trabalho da equipe e o clima da unidade, porém precisam superar para ajudar outras crianças (SOUZA PSN e CONCEIÇÃO AOF, 2018).

A morte em UTI de crianças representa para os enfermeiros a interrupção da ordem natural do ciclo vital e, portanto, é pontual, foge do normal e causa angústia, tristeza e depressão. É um fenômeno obscuro, inexplicável, ao mesmo tempo, inevitável para esses profissionais. A sensação de impotência, vem acompanhada de desgaste físico e emocional diante da morte de uma criança, chegando a paralisar alguns que não encontram palavras para confortar a família. Nesse momento surge outro sentimento, o de dor, uma dor que não sabem explicar, pois reconhecem seu esforço para que isso não acontecesse e ao mesmo tempo se questionam se fizeram realmente tudo que podiam e deviam para salvar aquela criança (SUBUTZKI LS, et al., 2018).

Vivenciam nesse momento um novo estado interior que transcende a compreensão humana, pensam nas suas próprias relações com as pessoas próximas a eles e sentem como precisam melhorar a relação com aqueles que estão junto no seu dia a dia. É um despertar para autorreflexão em relação ao trabalho, familiares, atitudes pessoais e profissionais. Essa dimensão também é evidenciada na medida em que traduzem a morte como uma "passagem" para um local onde não mais haverá dor e sofrimento, um encontro com Deus (SUBUTZKI LS, et al., 2018).

Quando a morte é de recém-nascido, esse momento é vivenciado como um momento incompreensível, confuso que muda o curso natural da vida que é os pais morrerem antes dos filhos. O sentimento vivenciado é de frustação pela perda, visto que se envolvem emocionalmente com os bebês e com a família. Sabem que se distanciar é preciso, como uma forma de proteção, mas reconhecem que é difícil, pois não conseguem compreender e lidar com esse momento, pois não se sentem preparadas para lidar com a morte (SILVA IN, et al., 2017).

Outro aspecto que causa ansiedade nos enfermeiros foi a implantação de cuidados paliativos no contexto da UTI, pois isso não foi discutido com eles, não acontece um planejamento para o bebê em final de vida e a deficiência de comunicação entre a equipe multiprofissional, resulta em um processo de tomada de decisões diferentes entre a equipe (SILVA IN, et al., 2017).

Em cuidados paliativos na Unidade de Terapia Intensiva Neonatal (UTIN), os enfermeiros vivenciam um momento difícil, onde oferecem conforto e devem esconder a dor de saber que nada podem fazer para recuperar aquele bebê. Ao mesmo tempo, são os profissionais que mais se importam com eles, já que veem esses bebês serem os últimos a serem prescritos, meio que esquecidos e vivenciam um sentimento de pena pela família e pelo pequeno paciente (ALVES AMF, et al., 2018).

A finitude da vida infantil é difícil de aceitar, porém os enfermeiros reconhecem que aquele ser, necessita de seus cuidados e assim, enfrentam esse momento com força, seguram as lágrimas, procuram ter controle emocional para não afetar seu desempenho profissional, mesmo que se sintam impotentes. É o enfermeiro que tem de motivar sua equipe a continuar com harmonia e qualidade assistencial, propiciando conforto aquele pequeno paciente que está em fase final de vida. Pensam também na família e assim flexibilizam 
normas para que os pais possam passar mais tempo com seu filho. Oferecem a possibilidade de os pais carregarem seus filhos e até de expressarem sua dor, seu luto da forma de cada um (MENIN GE e PETTENON MK, 2015).

Uma revisão integrativa sobre o tema identificou temas recorrentes na vivência dos enfermeiros que convivem com a morte em UTIN, que vão desde a formação inadequada dos enfermeiros sobre a morte, quanto a frustação, a tristeza e o estresse diante da morte de uma criança. É a vivência mais difícil no cotidiano desses profissionais, eles se sentem fragilizados e assustados, representando esse momento como um insucesso da equipe, uma limitação profissional. Para os enfermeiros, a perda de um paciente na UTIN gera uma sensação de vazio e ter que cuidar daquele corpo pós-morte é uma tarefa desgastante (ROCHA DD, et al., 2017).

Observou-se no estudo, que os enfermeiros lidam com a dificuldade de dar a notícia da morte para a família, assim como, sentem dificuldades em reconhecer os limites das medidas terapêuticas e que não conseguem encarar com naturalidade o evento da morte. Diante do processo de morte, os enfermeiros se sentem impotentes, sentem culpa e raiva, apesar da morte ser uma prerrogativa de seu trabalho (ROCHA DD, et al., 2017).

Portanto, a vivência do processo de morte pelos enfermeiros em UTIN é mediada por tristeza, impotência, angústia, estresse que mobilizam os profissionais de diferentes formas, uns procuram enfrentar e confortar os pais, outros preferem se afastar para se proteger. Porém, para todos é um momento difícil, incompreensível que demonstra as limitações terapêuticas. O segundo tema a seguir, caracteriza essa vivência em UTI de adultos.

\section{Tema 2: Quando a morte vence a tecnologia assistencial.}

A vivência dos enfermeiros diante da morte em UTI de adultos, também é de sofrimento, de perda e as vezes de alívio. A morte nessa unidade é uma possibilidade concreta, embora seja uma unidade provida de tecnologia e especialização para recuperação dos que lá passam. O fato de vivenciar a morte como uma possibilidade real, onde as vezes chega como alívio para o paciente, é considerado como uma forma de proteção que esses profissionais desenvolvem para se proteger do sofrimento psíquico que a perda do paciente traz, apesar de todo aparato tecnológico existente nessas unidades para o cuidado deles, portanto, sentem-se fracassados e impotentes (SILVA CRL, et al., 2016).

Quando esse encontro do enfermeiro com o processo de morte se dá a partir de pacientes com fora de possibilidades terapêuticas, ele enfrenta cuidando para que o paciente chegue a sua finitude sem dor, sem sofrimento, sem complicações decorrentes da internação as vezes prolongada, porém o sentimento é de tristeza, frustração, despreparo para lidar com a morte e impotência, pois trabalhar em UTI remete em recuperar o paciente e não em morte (SILVA RS, et al., 2015).

Porém, quando essa experiência é vivenciada pelos enfermeiros no início da profissão, são consideradas mais difíceis, e acabam levando a angústia, a frustração e a tristeza para sua vida pessoal, visto que ainda não estão habituados e amadurecidos para lidar com essa situação. Os enfermeiros com mais tempo de serviço vivenciam de forma mais serena, pois já vivenciaram várias situações parecidas. De qualquer forma é um evento que abate a enfermagem pois, apesar do uso de todos os recursos que a unidade possui para tratar e recuperar, de nada vale para esses pacientes, restando o cuidado de enfermagem de conforto, de alívio e a aceitação do inevitável. Essa aceitação é mais fácil quando o paciente é idoso e mais difícil quando o paciente ainda é jovem (COSTA MRE, et al., 2017).

No cotidiano desse processo, os enfermeiros estabelecem uma relação de empatia com o paciente e seus familiares, oferecendo apoio, assim como, se preocupam com sua equipe, em prepará-los para a perda dos pacientes, embora tenham dificuldade em aceitar a irreversibilidade do estado do paciente. Mesmo os enfermeiros mais experientes, vivenciam esse momento com angústia, desânimo, impotência e frustração, uma vez que a UTI é vista com recursos necessários para a recuperação dos pacientes (COSTA MRE, et al., 2017). 
A vivência dos enfermeiros frente ao processo de morte de pacientes em cuidados paliativos faz também, com que se sintam inseguros, mas ao mesmo tempo fortes, pois apesar da tristeza, sabe que fez todos os cuidados com o paciente, mas sensibilizam-se com o sofrimento da família e assim procuram dar conforto as mesmas (SILVEIRA NR, et al., 2016).

Por outro lado, os enfermeiros se deparam nessas unidades com pessoas em processo de envelhecimento, onde a tecnologia da UTI prolonga a vida, então se deparam utilizando todos os recursos tecnológicos relacionados ao suporte avançado de vida, mas nem sempre é possível salvar e isso é frustrante (CRUZ EJER, et al., 2014).

Em um estudo de revisão bibliográfica, é identificado que os enfermeiros e demais profissionais de saúde vivenciam a morte na UTI com sentimento de impotência, frustração, angústia e ansiedade por não cumprirem a missão de manutenção da vida (DANTAS MAA et al., 2017). Outro estudo de revisão bibliográfica conclui que os profissionais de enfermagem não se sentem preparados para lidar com o processo de fim da vida e como fazer para enfrentar este momento (PERBONI JS, et al., 2018).

Observou-se que os enfermeiros vivenciam o processo de morte na UTI adulto como uma possibilidade concreta, porém se questionam que, frente a toda tecnologia disponível nas mesmas, nem sempre podem manter a vida ou recuperar a saúde dos pacientes. Lidam com respeito e empatia com os pacientes fora de possibilidades terapêuticas, dando cuidados de conforto, alívio de sofrimento e preservando a integridade física e emocional do paciente, preocupando-se ainda, em fornecer conforto a seus familiares e apoio a sua equipe de trabalho.

\section{DISCUSSÃO}

O final da vida é tema extremamente complexo, controverso e polêmico, pois envolve todas as pessoas em todas as sociedades, dado que todos, mais cedo ou mais tarde, têm de enfrentar seu próprio fim da vida. Porém, ainda que os seres humanos temam a morte, em algumas circunstâncias podem trazer alívio pelo fim do sofrimento. Já para profissionais da saúde, a morte de pacientes gera frustração, sensação de derrota e de incapacidade (SOUZA PSN e CONCEIÇÃO AOF, 2018).

Essa constatação vai ao encontro do que foi evidenciado no estudo, que os enfermeiros vivenciam esse momento com apreensão, angústia, ansiedade, tristeza e frustação. Em alguns casos, aceitam a morte como um evento que traz alívio ao sofrimento do paciente, principalmente no caso de pacientes em cuidados paliativos ou idosos. Isso porque, a morte traz consigo um sentimento de impotência e de culpa, principalmente quando ocorre um processo de morte sofrido ou precoce, e na avaliação da equipe, nada pode ser feito (BARBOSA AMGC e MASSARONI L, 2016).

Sobre os pacientes dado como fora de possibilidades terapêuticas, evidenciou-se que os enfermeiros cuidam deles como cuidam dos demais, garantindo a morte digna e sem sofrimento. Sobre isso, é preponderante ressaltar que a morte é um fato inevitável para todos, faz parte do ciclo vital e é um equívoco acreditar que nada mais pode ser feito ao paciente fora de possibilidade de cura, pois, enquanto há vida, existe a necessidade do cuidado. Dessa forma é dever do enfermeiro e sua equipe prestar cuidados ao paciente durante todo o seu tratamento, especialmente quando não é mais possível a cura e o doente é submetido a cuidados paliativos (SILVA RS, et al., 2011).

O fato da UTI ser um local onde existe todo um aparato tecnológico voltado para manutenção da vida e recuperação da saúde, faz com que os enfermeiros se sintam limitados e impotentes quando perdem um paciente, o que vai ao encontro do que refere Portela NLC (2015), quando afirma que, a sensação de impotência surge em decorrência da educação mecanicista. A tentativa de manutenção da vida do paciente a todo custo, por meio da utilização dos equipamentos tecnológicos, muitas vezes provoca estresse no profissional e acentua o seu sofrimento, além de tirar a dignidade do paciente, que não possui mais o direito de opinar, como se a vida já não lhe pertencesse. Apesar de a morte fazer parte do cotidiano da equipe de 
enfermagem, esta passa por um período de negação, pois a equipe possui a consciência de que está trabalhando pela vida, recusando-se, assim, a aceitar a morte.

Além de cuidar do paciente, o enfermeiro tem ainda de pensar na família e na sua equipe de trabalho, sobre isso, Freitas TLL, et al. (2016) ressalta que, no que tange a área da saúde, pode-se afirmar que a equipe de enfermagem é a mais próxima nas situações críticas com iminência de morte, é quem o paciente e as famílias procuram, quando precisam de explicações, amparo, cuidado físico e psicológico. Sendo que, o profissional deve lidar com o sofrimento, com a aflição e com os receios que podem existir, nos mais diversos momentos que envolvem o cuidar. Esses cuidados para serem eficazes exigem do enfermeiro não somente conhecimento das técnicas e da doença entre si, mas também habilidades para trabalhar com os sentimentos dos outros e com suas emoções perante o paciente com ou sem probabilidade de cura.

Vivenciar a UTI como uma realidade em que a morte é fato concreto, de certa forma protege os profissionais do sofrimento psíquico inevitável diante do processo de morte e nesse contexto, Vicensi MC (2016) ressalta que, a enfermagem acompanha de perto o cotidiano dos pacientes e familiares nessa unidade, e por mais que se tente evitar pensar na morte é inevitável, pois abriga pacientes graves e as vezes terminais, dessa forma o fim apresenta-se como possibilidade real onde se pode sentir sua presença.

Todos esses aspectos, observados com o estudo é corroborado no estudo de um clássico "Dor e Morte como Ofício" onde a autora, Ana Pitta, em uma pesquisa com trabalhadores de hospitais, identificou sentimentos desses profissionais que lidam cotidianamente com doenças e mortes. Entre esses sentimentos identificou: piedade, compaixão e amor, culpa e ansiedade, ódio e ressentimento. A autora citada, deixa claro que a natureza do trabalho, ao lidar com dor, sofrimento e morte, influencia a produção de sintomas psíquicos. As enfermeiras em particular, os pacientes e parentes também expressam apreço, afeição, respeito e gratidão. Mas tais sentimentos não impedem o ressentimento de dependência dos pacientes. Esses sentimentos dos pacientes e parentes, angustiam, confundem e com frequência levam sofrimento às enfermeiras (PITTA A, 1990).

\section{CONSIDERAÇÕES FINAIS}

Concluiu-se, que a vivência desse processo seja em UTI pediátrica, neonatal ou de adultos é um momento de tristeza, angústia e estresse. É vivenciado com certa incompreensão diante da morte de recém-nascidos, crianças e jovens por subverter o ciclo natural de vida. No cuidado ao paciente em processo final de vida, cuidam para manter a integridade física e emocional do paciente, dando conforto, alívio a suas dores, evitando complicações, como fazem com qualquer outro paciente, demonstrando que há muito a fazer por esses pacientes até que chegue a finitude da vida. Fazem isso com empatia e competência profissional sem, contudo, deixar de sentir compaixão pelo paciente e seus familiares. Por fim, é evidente o papel importante do enfermeiro nesse processo que não acaba com a cessação da vida, pois é preciso cuidar do corpo pósmorte, desligar aparelhos, retirar cateteres, limpar, lavar e entregar a família seu ente querido, não da forma que gostariam, mas é preciso que assim o façam.

\section{REFERÊNCIAS}

1. ALVES AMF, et al. Entre o nascer e o morrer: cuidados paliativos na experiência dos profissionais de saúde. Revista Brasileira em Promoção Saúde, 2018; 31(1): 1-10.

2. BARBOSA AMGC, MASSARONI L. Convivendo com a morte e o morrer. Revista de enfermagem UFPE on line, 2016; 10(2): 457-463.

3. BARRETO VPDC, et al. Estresse ocupacional na enfermagem e mindfulness : o que há de novo? Revista Enfermagem Atual, 2017; 80(18): 40-47.

4. COSTA MRE, et al. Sofrimento moral dos Enfermeiros em situações de final de vida em unidades de terapia intensiva. Revista de enfermagem UFPE on line, 2017; 11(9): 3607-3616. 
5. CRUZ EJER, et al. Dialectic feelings of the intensive care nurse about the work in Intensive Care. Escola Anna Nery Revista de Enfermagem, 2014; 18(3): 479-485.

6. DANTAS MAA, et al. Enfrentamento da morte: enfermagem na unidade de terapia intensiva. Congr Bras Cienc Saúde, 2017; 2(1): 2-11.

7. FREITAS TLL, et al. La visión de la Enfermería ante el Proceso de Muerte y Morir de pacientes críticos: una revisión integradora. Enfermería Global, 2016; 41: 163-170.

8. MENDES KDS, et al. Revisão integrativa: método de pesquisa para a incorporação de evidências na saúde e na enfermagem. Texto \& Contexto Enfermagem, 2008; 17(4): 758-764.

9. MENIN GE, PETTENON MK. Terminalidade da vida infantil: percepções e sentimentos de enfermeiros. Revista Bioética, 2015; 23(3): 608-614.

10. MONTEIRO MC, et al. A Morte em Cena na UTI: A Família Diante da Terminalidade. Trends in Psychology, 2017; 25(3): 1285-1299.

11. PERBONI JS, et al. Profissionais de saúde e o processo de morte e morrer dos pacientes: uma revisão integrativa. Persona y Bioética, 2018; 22(2): 288-302.

12. PITTA A. Hospital: dor e morte como ofício. São Paulo: HUCITEC, 1990.

13. PORTELA NLC. Profissionais de enfermagem e a morte em unidade de terapia intensiva. Revista Augustus, $2015 ; 19(38): 36-43$.

14. ROCHA DD, et al. Sentimentos vivenciados pelos profissionais de Enfermagem diante de morte em unidade de terapia intensiva neonatal. Mental, 2017; 11(21): 546-560.

15. SANTOS MR, et al. Da hospitalização ao luto: significados atribuídos por pais aos relacionamentos com profissionais em oncologia pediátrica. Revista da Escola de Enfermagem da USP [online], 2019; 53:e03521.

16. SILVA CRL, et al. Representações sociais de enfermeiros sobre o processo de morte e morrer em UTI. Ciência, Cuidado e Saúde, 2016; 15(3): 474.

17. SILVA RS, et al. Cuidando do paciente no processo de morte na Unidade de Terapia Intensiva. Revista da Escola de Enfermagem da USP, 2011; 45(3): 738-744.

18. SILVA RS, et al. Comfort for a good death: perspective nursing staff's of intensive care. Escola Anna Nery Revista de Enfermagem, 2015; 19(1): 40-46.

19. SILVA IN, et al. Knowing nursing team care practices in relation to newborns in end-of-life situations. Escola Anna Nery, 2017; 21(4): 1-8.

20. SILVA VA, et al. Características de cuidadores submetidos à musicoterapia após a morte de seus entes queridos. Revista Brasileira de Enfermagem [Internet], 2019; 72(6): 1464-1470.

21. SILVEIRA NR, et al. Cuidado paliativo e enfermeiros de terapia intensiva: sentimentos que ficam. Revista Brasileira de Enfermagem, 2016; 69(6): 1074-1081.

22. SOUZA MT, et al. Integrative review: what is it? How to do it? Einstein (São Paulo), 2010; 8(1): 102-106.

23. SOUZA PSN, CONCEIÇÃO AOF. Processo de morrer em unidade de terapia intensiva pediátrica. Revista Bioética, 2018; 26(1): 127-134.

24. SUBUTZKI LS, et al. Processo de morte e morrer em unidade de terapia intensiva neonatal à luz da complexidade. Revista de Pesquisa: Cuidado é Fundamental Online, 2018; 10(Especial): 25-28.

25. URSI ES, GAVÃO CM. Prevenção de lesões de pele no perioperatório: revisão integrativa da literatura. Revista Latino-Americana de Enfermagem, 2006; 14(1): 124-131.

26. VENTURA G, et al. Enfrentamento de enfermeiras frente à morte no processo de cuidar em emergencia. Enfermería Actual de Costa Rica, 2019; (37): 142-154.

27. VICENSI MC. Reflexão sobre a morte e o morrer na UTI: a perspectiva do profissional. Revista Bioética, 2016; 24(1): 64-72. 